\title{
Strategi pengembangan ekowisata Danau Masjid Kabupaten Kuantan Singingi
}

\author{
Irfan Yunus ${ }^{1}$, Zulfan Saam ${ }^{2}$, Yusni Ikhwan Siregar ${ }^{3}$ \\ ${ }^{1}$ Dinas Kelautan dan Perikanan Provinsi Riau \\ 2,3 Magister Ilmu Lingkungan, Program Pascasarjana Universitas Riau
}

\begin{abstract}
Masjid Lake is one of the Natural Tourism Objects in Riau Province, which is located in Kuantan Singingi Regency. This research is intended to determine the potential condition of the Koto Kari Mosque Lake area and its feasibility to be developed as an ecotourism object, identify and analyze tourist attractions, amenities and accessibility of ecotourism development, analyze the economic impact on ecotourism development, and formulate ecotourism development strategies in the Danau Masjid Regency area. Kuantan Singingi. The research method is a survey method by conducting direct field observations accompanied by interviews with the Kuantan Singingi Regency Government as managers, traditional and religious leaders. Traditional and religious leaders were used as representatives of the community to fill out the questionnaire. Respondents consisted of four traditional leaders and one religious leader, and the sampling was conducted at three station locations in the north, west and east which were seen based on differences in characteristics possessed in the tourist area of the Koto Kari Mosque Lake. To obtain an overview of the strategy to be used, an analysis was carried out with several stages and was guided by the FMU development design model $S$ and the formulation of strategies from the data and information obtained were analyzed using the SWOT method, namely by analyzing internal and external factors owned by the Danau Mesjid Koto area. Curry. The results showed that the suitability of Koto Kari Mosque Lake tourism, at Station 1 which is located in the northern part, is categorized as suitable for all tourism activities, namely fishing (94.12\%), camping (86.27\%), water games (90.20\%)., sit back (91.67\%) and outbound (78.43\%) this is because this location has a depth of $1-2 \mathrm{~m}$, slope $<200$, clarity $>80 \%$, calm water, the view seen at this station is a stretch lakes, rice fields and rubber gardens. Whereas Station 2 in the western part has the appropriate conditional criteria for fishing tourism activities (94.12\%) and sitting back (90.20\%), because this location has a narrow lakeside and the historical building of the Old Koto Kari Mosque and residential housing in the outskirts of the lake, and at station 3 which is located in the eastern part are suitable for outbound activities, sitting back and camping with the percentage of $91.67 \%, 90.20 \%$ and $86.27 \%$, respectively. Based on observations and referring to the opinion of the local community, the lake waters have characteristics that are deep enough to be dangerous for boating and water games. Based on the results of the analysis of the carrying capacity in the Koto Kari Mosque Lake area, it is different at each station location. Station 1 based on the calculation of the Tourism Suitability Index value of this station is very suitable for fishing, camping, water games, sitting back and outbound, while station 2 is very suitable for fishing and sitting back, and at station 3 is suitable for outbound activities, sitting back and camping. . The results of the analysis of area management strategies for ecotourism using SWOT analysis resulted in 9 alternative strategies, but those that can be used as a top priority as a strategic plan for the development of the Koto Kari Mosque Lake tourism area, namely holding cooperation in promoting the Koto Kari Mosque Lake as a natural and sustainable tourism area. its resources, attracting investors for the development of Koto Kari Mosque Lake tourism while still paying attention to the preservation of its resources, as well as coordinating in overcoming problems and threats that exist in the Koto Kari Mosque Lake
\end{abstract}

Keywords: ecotourism; planning; implementation; monitoring; evaluation

Sektor pariwisata semakin menjadi andalan, harapan dan primadona bagi pemerintah setelah minyak dan gas. Kunjungan wisatawan manca negara dan perolehan devisa dari sektor ini semakin meningkat dari tahun ke tahun, dan menduduki peringkat ketiga dalam menghasilkan devisa non - migas setelah kayu lapis, tekstil dan garmen (Yoeti dalam Dewi, 2003).

Pengembangan pariwisata agar menjadi pariwisata yang maju tentunya tidak bisa hanya mengandalkan kegiatan wisata yang ada saja. Diperlukan beberapa pengembangan kegiatan wisata yang beragam untuk memberikan alternatif bagi pengunjung yang datang ke kota ini. Salah satunya yang saat ini sangat potensial untuk dikembangkan adalah wisata alam.

Kehadiran ekowisata dalam era pembangunan berwawasan lingkungan merupakan suatu misi pengembangan pariwisata alternatif yang tidak banyak menimbulkan dampak negatif, baik terhadap maupun terhadap sosial budaya dan daya tarik wisata lainnya. Kegiatannya lebih berorientasi pada pemanfaatan sumber daya alami, asli dan belum tercemar. Banyak negara yang menjadikan sektor pariwisata sebagai bisnis unggulan dalam dunia ekonomi yang dapat memberikan kontribusi di atas $10 \%$ 
bagi GDP (Gross Domestic Product) berdasarkan data TIES (The International Ecotourism Society Factsheet : Global Ecotourism 2008).

Pentingnya lingkungan alam untuk mendukung suatu kawasan menjadi daerah tujuan atau objek wisata tidak terbantahkan lagi. Meskipun bukan faktor utama atau satu-satunya yang menarik wisatawan untuk berkunjung, tetapi faktor lingkungan dan alam mempunyai pengaruh signifikan bagi calon wisatawan mengapa memilih daerah tersebut sebagai daerah tujuan wisata. Disisi lain tidak dapat dipungkiri juga aktifitas pariwisata di suatu kawasan akan menimbulkan dampak terhadap alam dalam derajat tertentu. Hal inilah yang menjadi perhatian besar agar pembangunan pariwisata tidak berdampak negatif bagi lingkungan dan menurut Richardson dan Fluker (2004).

Kabupaten Kuantan Singingi Salah satu kabupaten yang berada di Provinsi Riau memiliki cukup banyak daerah tujuan wisata, satu diantaranya adalah wisata alam yang berupa Danau Masjid yang terletak di Desa Koto Kari Kecamatan Kuantan Tengah. Pada sore hari Danau Masjid ini ramai dikunjungi oleh pengunjung. Selain Danau Masjid, Kabupaten Kuantan Singingi juga mempunyai objek wisata Danau Kebun Nopi yang terletak di Desa Bukit Pedusunan Kecamatan Kuantan Mudik. Jika dibandingkan dengan Danau Masjid, Danau Kebun Nopi mendapat priotas utama untuk lebih dahulu dikelola dan dikembangkan oleh Pemerintah Kabupaten Kuantan Singingi karena berbagai pertimbangan. Pertimbangan yang mendasar adalah Danau Kebun Nopi merupakan tempat pertandingan dayung PON Tahun 2012 lalu.

Danau Mesjid terletak di Desa Koto Kari yang berjumlah penduduk \pm 1.200 orang ini terletak di Kecamatan Kuantan Tengah \pm 4,6 Km dari ibu kota Kabupaten Teluk Kuantan. Sekitar Danau Mesjid ini sudah dibebaskan lahan oleh Pemerintah Kabupaten Kuantan Singingi Tahun 2011. Dalam perjalanan ke Danau Masjid ini kita menyaksikan hamparan sawah yang menguning, air danau yang tenang dan ada tempat rekreasi seperti speed boat untuk berkeliling sekitar Danau Masjid ini, rumah pohon, warungwarung tempat berjualan dan menyaksikan binatang kera, berbagai jenis burung dan binatang lainnya seakan menyapa bagi pengunjung (Hendrianto, 2009).

Ekowisata Danau Masjid pada saat ini sudah didukung oleh fasilitas yang memadai. Untuk menuju objek ini, para pengunjung sudah melewati jalan yang sudah beraspal. Dalam pengembangan dan pengelolaannya harus dapat menyeimbangkan berbagai aspek saling mempengaruhi diantaranya aspek sosial, ekonomi dan lingkungan. Pengembangan ekowisata ini akan berorientasi kepada bagaimana mendatangkan uang dari objek wisata ini sehingga pemerintah daerah mendapatkan pemasukan untuk kas daerah dan juga bagaimana masyarakat mendapatkan keuntungan dari pengembangan ekowisata ini. Jadi, untuk pengembangan Danau Masjid yang dapat bermanfaat bagi semua pihak, maka rumusan masalah yang perlu dikaji adalah:

Adapun tujuan penelitian ini untuk Mengetahui kondisi potensi kawasan Danau Masjid dan kelayakannya untuk dikembangkan sebagai objek ekowisata. Mengidentifikasi dan menganalisis kesesuaian kawasan wisata dan daya dukung kawasan wisata pengembangan ekowisata di kawasan Danau Masjid Kabupaten Kuantan Singingi. Menganalisis dampak ekonomi terhadap pengembangan ekowisata Danau Masjid Kabupaten Kuantan Singingi.Merumuskan strategi pengembangan ekowisata di kawasan Danau Masjid Kabupaten Kuantan Singingi.

Penelitian ini diharapkan dapat menjadi masukan bagi Pemerintah Kabupaten Kuantan Singingi dalam rangka pelestarian Kawasan Danau Masjid, dan dalam rangka pengembangan kawasan sebagai objek wisata unggulan di Kabupaten Kuantan Singingi. Sedangkan bagi kalangan akademis, hasil penelitian diharapkan dapat menjadi bentuk pengayaan dalam pemilihan alternatif strategi pengembangan kawasan dan menjadi dasar bagi penelitian mengenai pengelolaan kawasan berbasis ekowisata serta wiraswasta dan pemerintah.

\section{METODA PENELITIAN}

\section{Waktu dan Lokasi Penelitian}

Penelitian ini dilaksanakan pada bulan September - Desember 2018 di kawasan wisata Danau Masjid Desa Koto Kari, Kecamatan Kuantan Tengah, Kabupaten Kuantan Singingi. 
Danau Masjid Koto Kari terdapat di Desa Koto Kari Kecamatan Kuantan Tengah yang mempunyai luas wilayah seluas 415 hektar. Jarak Desa Koto Kari, ke ibukota kecamatan adalah 4,6 km, jarak Desa Koto Kari ke ibukota kabupaten adalah 4,6 km. Secara geografis Danau Mesjid terletak pada $101^{0} 33^{\prime} 20^{\prime \prime}-101^{0} 33^{\prime} 00^{\prime \prime}$ BT dan $0^{0} 33 ; 20^{\prime \prime}-0^{0} 33^{\prime} 00^{\prime \prime}$ LS. Daerah aliran sungai yang mengaliri menuju Danau Masjid keseluruhannya seluas 155,6 ha. Luas penutupan lahan terdiri dari 5,6 ha (luas genangan), pemukiman seluas 46,1 ha, pertanian seluas 97,4 ha dan lahan terbuka seluas 6,4 ha

\section{LOKASI PENELITIAN DANAU MASJW KOTO KARI}

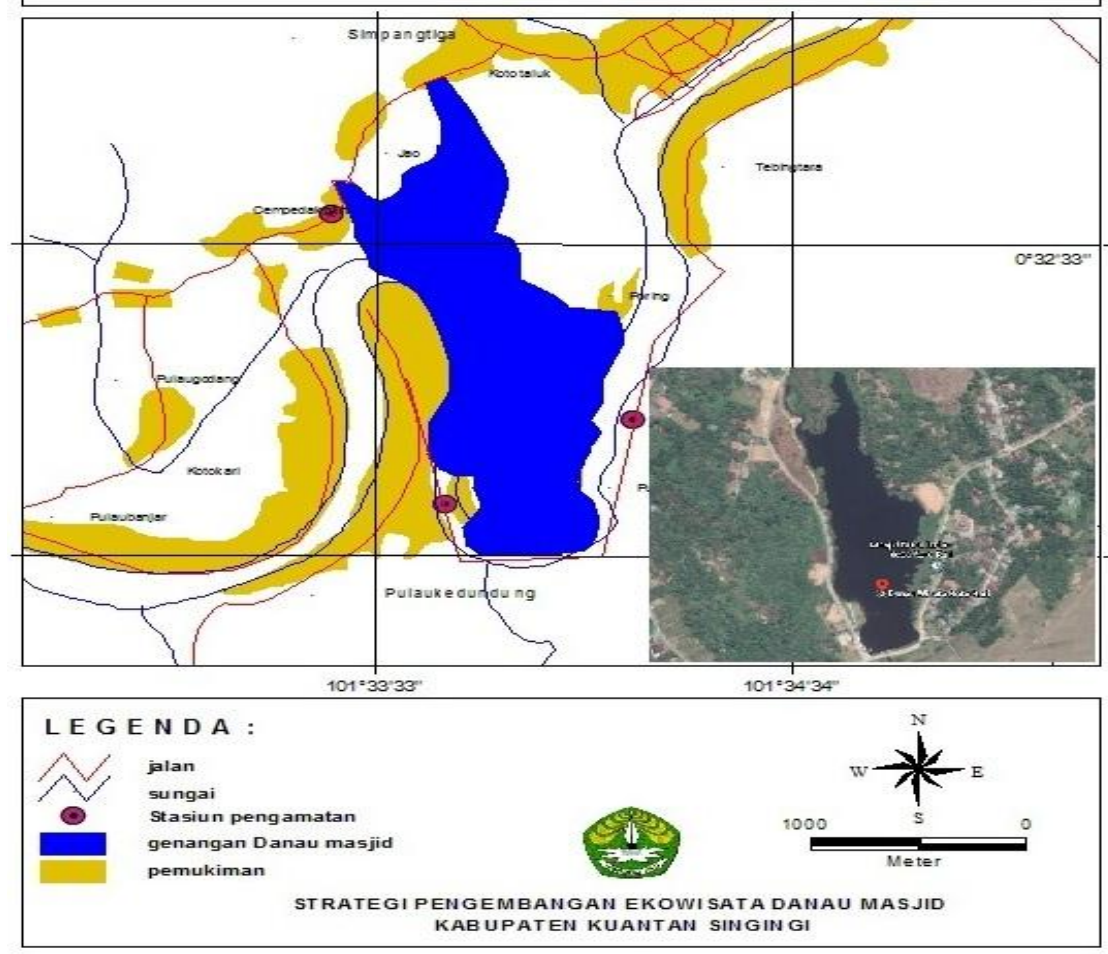

Gambar 1. Peta Lokasi Penelitian Danau Masjid Koto Kari

\section{Metode Penelitian}

Disamping itu dihimpun juga data sekunder dari sumber data di lokasi survey. Subiyanto (2000) mengatakan bahwa metode penelitian dengan metode survey sebagai perancangan penelitian dengan tujuan melakukan pengujian yang cermat dan teliti terhadap suatu objek penelitian berdasarkan suatu situasi ataupun kondisi tertentu dengan melihat kesesuainnya dengan pertanyaan atau nilai tertentu.

Wawancara dilakukan dengan perwakilan dari pihak pengelola, instansiinstansi terkait, masyarakat setempat dan wisatawan. Khusus untuk masyarakat setempat/sekitar dan wisatawan, wawancara dilakukan melalui pengisian kuesioner dengan pertanyaan-pertanyaan yang berkaitan dengan kawasan wisata Danau Masjid. Masyarakat sekitar Danau Masjid dan wisatawan yang diwawancarai (responden) masing-masing berjumlah 30 orang. Daftar pertanyaan dan kuesioner yang digunakan disajikan pada Lampiran. Penentuan responden ditetapkan melalui metode purposive sampling yaitu anggota populasi sengaja dipilih untuk memenuhi tujuan tertentu dengan mengandalkan logika atas kaidah-kaidah yang berlaku dan berdasarkan atas judgement peneliti. Dengan demikian, responden yang dipilih sudah mempunyai persepsi terhadap kawasan wisata Danau Masjid sehingga diharapkan mampu menjawab pertanyaan yang diajukan (Fauzi 2001 in Nancy 2007). 
Tabel 1. Jenis Data Primer dan Data Sekunder yang dikumpulkan

\begin{tabular}{|c|c|c|c|c|c|}
\hline No & Komponen & Jenis Data & \multicolumn{2}{|l|}{ Sumber Data } & $\begin{array}{c}\text { Teknik } \\
\text { Pengambilan } \\
\text { Data }\end{array}$ \\
\hline 1. & Keadaan umum kawasan wi & ata danau masji & desa koto kari & & \\
\hline a. & Kondisi fisik kawasan & $\begin{array}{l}\text { Primer dan } \\
\text { Sekunder }\end{array}$ & Laporan & & $\begin{array}{l}\text { Observasi } \\
\text { langsung dan } \\
\text { Studi pustaka }\end{array}$ \\
\hline b. & Demografi & Sekunder & Laporan & & Studi pustaka \\
\hline c. & Sarana prasarana & $\begin{array}{l}\text { Primer dan } \\
\text { Sekunder }\end{array}$ & $\begin{array}{l}\text { Responden } \\
\text { Laporan }\end{array}$ & dan & $\begin{array}{l}\text { Observasi } \\
\text { langsung dan } \\
\text { Studi pustaka }\end{array}$ \\
\hline 2. & Sumberdaya Alam & & & & \\
\hline a. & $\begin{array}{l}\text { Flora (Vegetasi dan tum- } \\
\text { buhan air) }\end{array}$ & $\begin{array}{l}\text { Primer dan } \\
\text { Sekunder }\end{array}$ & $\begin{array}{l}\text { Responden } \\
\text { Laporan }\end{array}$ & dan & $\begin{array}{l}\text { Observasi } \\
\text { langsung dan } \\
\text { Studi pustaka }\end{array}$ \\
\hline b. & $\begin{array}{l}\text { Fauna (Ikan dan biota air } \\
\text { lainnya) }\end{array}$ & $\begin{array}{l}\text { Primer dan } \\
\text { Sekunder }\end{array}$ & $\begin{array}{l}\text { Responden } \\
\text { Laporan }\end{array}$ & dan & $\begin{array}{l}\text { Observasi } \\
\text { langsung dan } \\
\text { Studi pustaka }\end{array}$ \\
\hline
\end{tabular}

Penyusunan strategi dalam rangka pencapaian tujuan pengembangan ekowisata Danau Masjid Kabupaten Kuantan Singingi adalah upaya memanfaatkan kekuatan dan peluang yang ada guna mengeliminasi kelemahan dan ancaman yang dihadapi. Penyusunan strategi dari data dan informasi yang diperoleh dianalisis dengan metoda SWOT, yang mempertimbangkan aneka faktor yang berperan negative atau positif : kekuatan, kelemahan, kesempatan dan ancaman objek wisata tersebut. Analisis SWOT digunakan untuk mengidentifikasi relasi - relasi sumberdaya ekowisata dengan sumberdaya yang lain (Damanik dan Weber, 2006). Melalui proses tersebut akan dilakukan penarikan kesimpulan berupa strategi pengembangan ekowisata Danau Masjid di Kabupaten Kuantan Singingi. Di dalam analisis SWOT ada sejumlah unsur dan variable yang mutlak menjadi fokus kajian, yaitu :

Tabel 2. Beberapa Unsur dan Variabel Dalam Analisis SWOT Ekowisata

\begin{tabular}{ll}
\hline \multicolumn{1}{c}{ Unsur } & \multicolumn{1}{c}{ Variabel } \\
\hline Keaslian dan kealamian & Kondisi ekosistem \\
Keunikan & Keberadaan biota yang menjadi ciri khas \\
Kawasan jelajah & Wilayah jelajah \\
Keindahan alam & Panorama alam \\
Kenyaman & Kenyamanan alami \\
Aspirasi masyarakat & Untung rugi bagi masyarakat sekitarnya \\
Daya tarik alam & Lokasi, jenis \\
Budaya (pendukung) & Lokasi, jenis \\
Potensi perubahan lingkungan & Perubahan lingkungan fisik, ekologis \\
Aksesibilitas & Daya angkut, akses, mutu, frekuensi, ongkos \\
Promosi/ informasi wisata & Mutu, informasi, publisitas, model promosi \\
Sumber daya manusia & Petugas lapangan \\
Komitmen pemerintah & Program pengembangan \\
Potensi wisata domestic & Jumlah \\
Potensi riset dan konservasi & Originalitas \\
Penegakkan hukum & Sanksi pengrusakan \\
Sumber air & Ketersediaan \\
Ketertiban & Menjaga fasilitas yang tersedia \\
Fasilitas & Jenis, jumlah, pemanfaatan \\
\hline Sumber : Yuanike (2002) dan Gunn (2002) &
\end{tabular}




\section{Kualitas Air Perairan}

\section{HASIL DAN PEMBAHASAN}

Berdasarkan data sekunder hasil penelitian Zulkarnaini (2020), kondisi fisik perairan di Danau Masjid cukup mendukung untuk pengembangan ekowisata. Hal ini ditandai kedalaman danau pada kondisi normal berkisar antara 0 - 5 meter, kecepatan arus $0,15 \mathrm{~m} /$ detik, warna perairan jernih dan tidak berbau.

Tabel 3. Kondisi Fisik Perairan di Danau Masjid

\begin{tabular}{ccccccccccccc}
\hline \multicolumn{3}{c}{ Kedalam Air } & \multicolumn{3}{c}{ Kecepatan Arus } & \multicolumn{3}{c}{ Warna Perairan } & \multicolumn{3}{c}{ Bau Perairan } \\
\hline $\begin{array}{c}\text { Kelas } \\
(\mathrm{m})\end{array}$ & Ha & $\%$ & $\begin{array}{c}\text { Kelas } \\
(\mathrm{m} / \mathrm{dt})\end{array}$ & Ha & $\%$ & Kelas & Ha & $\%$ & Kelas & Ha & $\%$ \\
\hline $0-5$ & 23 & 100 & $<0.15$ & 23 & 100 & $\mathrm{~J}$ & 23 & 10 & $\mathrm{~TB}$ & 23 & 100 \\
$5-7$ & 0 & 0 & $0,15-0,30$ & 0 & 0 & SK & 0 & 0 & 0 & 0 & 0 \\
$7-10$ & 0 & 0 & $0,30-0,45$ & 0 & 0 & K & 0 & 0 & 0 & 0 & 0 \\
$>10$ & 0 & 0 & $>45$ & 0 & 0 & SGK & 0 & 0 & 0 & 0 & 0
\end{tabular}

Keterangan :

$\mathrm{J}=$ Jernih, $\mathrm{SK}=$ Sedikit Keruh, $\mathrm{K}=$ Keruh, $\mathrm{SGK}=$ Sangat Keru, $\mathrm{TB}=$ Tidak berbau, $\mathrm{SB}=$ Sedikit Berbau, B=Berbau dan SGB= Sangat Berbau

Sumber : Zulkarnaini (2020)

\section{Morfometri dan Morfologi Danau}

Berdasarkan hasil analisis peta tanah skala detail skala semi detail 1:50.000 diketahui bahwa jenis tanah di Danau Masjid di dominasi jenis tanah inceptisol, entisol dan sebagian kecil latosol. Sebagian besar tanah bertekstur lempung berpasir $(54,8 \%)$ dan lempung berdebu $(45,2 \%)$. Kelerengan di lokasi Danau Masjid termasuk kategori datar dengan kelerengan $<5 \%$. Sedangkan curah hujan di Danau Masjid termasuk kategori basah dengan curah hujan di atas $1729 \mathrm{~mm} /$ tahun.

Tabel 4. Kondisi Geofisik di Sekitsr Danau Masjid

\begin{tabular}{ccccccccc}
\hline & Tanah & \multicolumn{3}{c}{ Kelerengan } & \multicolumn{3}{c}{ Curah Hujan } \\
\hline Kelas & Ha & $\%$ & $\begin{array}{c}\text { Kelas } \\
(\%)\end{array}$ & Ha & $\%$ & $\begin{array}{c}\text { Kelas } \\
(\mathrm{mm} / \mathrm{th})\end{array}$ & Ha & $\%$ \\
\hline ld & 10,4 & 45,2 & $0-5$ & 23 & 100 & $<1540$ & 0 & 0 \\
lp & 12,6 & 54,8 & $5-25$ & 0 & 0 & $1540-1632$ & 0 & 0 \\
pd & 0 & 0 & 0 & 0 & 0 & $1632-1729$ & 0 & 0 \\
p & 0 & 0 & 0 & 0 & 0 & $>1729$ & 23 & 100 \\
\hline
\end{tabular}

Keterangan :

$\mathrm{lp}=$ Lempung berdebu, $\mathrm{lp}=$ lempung berpasir, $\mathrm{pd}=$ pasir berdebu, $\mathrm{p}=$ pasir

Sumber : Zulkarnaini (2020)

Lokasi tanah berpasir dengan kelerengan yang datar akan mendukung pengembangan Danau Masjid sebagai tempat perkemahan karena drainase tanah akan sangat cepat terserap oleh tanah, sedangkan intensitas curah hujan yang tinggi akan mendukung supply air secara kontinyu ke Danau Masjid. Namun demikian curah hujan yang tinggi memerlukan pengelolaan aliran air secara baik mengingat lokasi Danau Masjid yang begitu dekat dengan aliran sungai Indragiri berpotensi banjir. 


\section{Kesesuaian Wisata Danau Masjid Koto Kari}

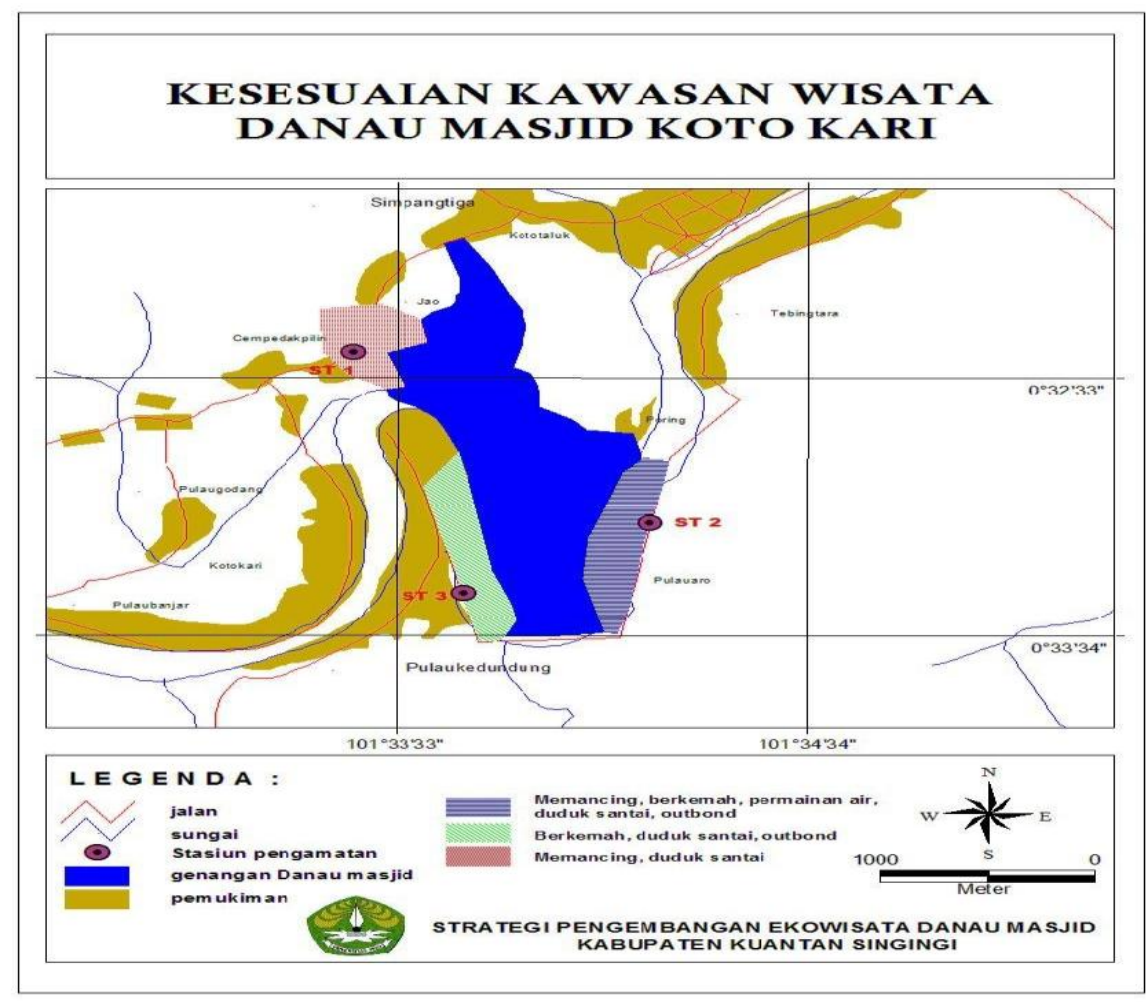

Gambar 2. Kesesuaian wisata Danau Masjid Koto Kari

Tabel 5. Kriteria Indeks Kesesuaian Wisata (IKW di setiap stasiun penelitian

\begin{tabular}{clcc}
\hline Lokasi & Kegiatan wisata & \% IKW & Kategori IKW \\
\hline \multirow{3}{*}{ Stasiun 1 } & Memancing & 94.12 & $\mathrm{~S}$ \\
& Berkemah & 86.27 & $\mathrm{~S}$ \\
& Permainan Air & 90,20 & $\mathrm{~S}$ \\
& Duduk Santai & 91,67 & $\mathrm{~S}$ \\
& Outbound & 78,43 & $\mathrm{~S}$ \\
& Memancing & 94.12 & $\mathrm{~S}$ \\
Stasiun 2 & Berkemah & 74,07 & $\mathrm{SB}$ \\
& Permainan Air & 78,43 & $\mathrm{SB}$ \\
& Duduk Santai & 90,20 & $\mathrm{~S}$ \\
& Outbound & 78,43 & $\mathrm{SB}$ \\
& Memancing & 74,07 & $\mathrm{SB}$ \\
Stasiun 3 & Berkemah & 86,27 & $\mathrm{~S}$ \\
& Permainan Air & 78,43 & $\mathrm{SB}$ \\
& Duduk Santai & 90,20 & $\mathrm{~S}$ \\
& Outbound & 91,67 & $\mathrm{~S}$ \\
\hline
\end{tabular}

Keterangan : S = Sesuai, $\mathrm{SB}=$ Sesuai bersyarat

Sumber : Data primer (diolah)

Berdasarkan hasil analisis kesesuaian wisata :

Stasiun 1 dikategorikan sesuai untuk semua kegiatan wisata yaitu memancing $(94.12 \%$,), berkemah, (86. $27 \%$ ), permainan air $(90,20 \%)$, duduk santai $(91,67)$ dan outbound $(78,43)$. Hal ini di sebabkan karena lokasi satu memiliki parameter yang sangat sesuai dengan aktifitas wisata tersebut. Perairan danau di stasiun ini memiliki kedalaman 1-2 m, kelandaian < 200, kejernihan $>80 \%, 0.5-0.25 \mathrm{~m} / \mathrm{dtk}$, dan air yang tenang, lebar tepian $\geq 8 \mathrm{~m}$, pemandangan yang dapat dilihat dari lokasi ini berupa hamparan danau, sawah, dan kebun karet. Hamparan daratan yang berupa pasir dan tanah berumput. Menurut masyarakat tidak terdapat biota berbahaya di lokasi ini. 
Stasiun 2 memiliki kriteria sesuai bersyarat untuk kegiatan wisata memancing $(94.12 \%$, ) dan duduk santai $(90,20)$. Hal ini dapat disebabkan lokasi ini memiliki tepian danau yang sempit dan adanya bangunan sejarah Mesjid Tua Koto Kari serta perumahan penduduk di pinggiran danau.

Stasiun 3 yang terdapat di bagian utara sesuai untuk kegiatan outbound, duduk santai, dan berkemah dengan persentase berturut-turut $91.67 \%, 90.20 \%$, dan $86.27 \%$. Berdasarkan persentase tersebut kegiatan paling sesuai adalah kegiatan outbound dan berkemah karena persentasenya paling tinggi, tapi berdasarkan hasil pengamatan di lapangan dan pendapat yang mengacu dari masyarakat setempat, perairan Danau memiliki karakteristik yang cukup dalam sehingga agak berbahaya untuk kegiatan berperahu dan permainan air. Adanya pemandangan alam yang asri, aktifitas nelayan dapat memberikan kenyamanan bagi wisatawan ketika melakukan kegiatan wisata duduk santai di lokasi empat tersebut.

\section{Analisis Daya Dukung Kawasan}

Analisis daya dukung yang dimaksudkan adalah kemampuan kawasan untuk menerima sejumlah wisatawan dengan intensitas penggunaan maksimum terhadap sumberdaya alam yang berlangsung secara terus-menerus dalam satu hari tanpa merusak lingkungan (Soemarwoto 2004).

Analisis daya dukung di kawasan Danau Masjid Koto Kari diperlukan agar kegiatan wisata yang akan dikembangkan dapat terus berkelanjutan. Daya dukung setiap kawasan di Danau Masjid Koto Kari berbeda untuk setiap lokasi, hal ini terkait perbedaan luas wilayah dan jenis kegiatan yang akan dikembangkan

\section{KESIMPULAN}

Berdasarkan analisis, kesimpulan yang dapat diambil dari penelitian ini adalah sebagai berikut: Mengadakan kerjasama dalam promosi Danau Masjid Koto Kari sebagai kawasan wisata yang terjaga kealamian dan kelestarian sumberdayanya. Menarik investor untuk pengembangan wisata Danau Masjid Koto Kari dengan tetap memperhatikan kelestarian sumberdayanya. Melakukan koordinasi dalam mengatasi permasalahan dan ancaman yang terdapat di Danau Masjid Koto Kari. Melalui alternatif strategi ini diharapkan Danau Masjid Koto Kari akan menjadi kawasan wisata dengan konsep keberlanjutan, sehingga dapat menarik banyak wisatawan dan pada akhirnya dapat meningkatkan kesejahteraan masyarakat. Berdasarkan analisis SWOT diketahui bahwa status pengelolaan ekowisata di Danau Masjid saat ini termasuk dalam situasi menguntungkan karena memiliki lebih banyak kekuatan dan peluang usaha daripada kelemahan dan tantangan. Strategi yang harus digunakan untuk meningkatkan pengelolaan ekowisata di danau masjid adalah menggunakan kekuatan dan peluang yang ada untuk mengeleminasi kelemahan dan tantangan. Strategi tersebut dapat diimplementasikan melalui : (1) Penyusunan perencanaan terpadu yang menampung seluruh aspek-aspek pengembangan ekowisata berkelanjutan; (2) Menggunakan perencanaan terpadu sebagai dasar kelayakan pengembangan bisnis ekowisata di Danau Masjid berbasis masyarakat; (3) Meningkatkan kemampuan staf dan masyarakat untuk inovasi pengembangan ekowisata; (4) Menerapkan sistem pemasaran produk ekowisata berbasis digital dengan mempertimbangkan trend permintaan ekowisata; dan (5) Meningkatkan sistem akuntabilitas pengembangan ekowisata baik kepada masyarakat lokal yang terintegrasi dengan pembangunan desa dan membangun reputasi kepada wisatawan.

\section{DAFTAR PUSTAKA}

Heher, S. 2003. Ecotourism Invesment and Develomment Models: Donors NGOs and Private Enterpreneurs. Johnson Graduate School of Management, School of Hotel Administration Cornell University, Cornell.

TIES (The International Ecotourism Society Factsheet : Global Ecotourism 2008).

Destinasi pariwisata didefinisikan sebagai: "A significant place visited on a trip, with some form of actual or perceived boundary. The basic geographic unit for the production of tourism statitistics" (Ricardson dan Fluker, 2004: 48).

Hendrianto, 2009. Batangkoban Hulu Kuantan. D: \tesis ekowisata/batangkobanhulukuantan.html.diakses pada 20 Agustus 2009.] 


\section{ZONA}

Jurnal Lingkungan

Volume 3, No 1, April 2019, p. 10-17

ISSN : 2502-6496 (Print)

http://zona.pelantarpress.co.id

Sugiono. 2013. Metode Penelitian Pendidikan (Pendekatan Kuantitatif, Kualitatif dan R \& D). Bandung : Alfabeta.

Soemarwoto, Otto, 2004, Ekologi, Lingkungan Hidup dan Pembangunan. Jakarta : Djambatan 